\title{
Masa, calidad, direccionalidad. ¿Cuál es la verdadera diferencia entre 'osteopenias' y 'osteoporosis'?
}

\author{
Mass, quality, directionality \\ ¿Which is the real difference between 'osteopenias' and \\ 'osteoporoses'?
}

\begin{abstract}
José L. Ferretti ${ }^{1}$, Laura M. Nocciolinoํㅗ, Sergio H. Lüscher ${ }^{1}$, Leandro Mackler ${ }^{1}$, Raúl S. Beribé ${ }^{2}$, Romina González ${ }^{2,3}$, Nicolás Pilot ${ }^{2}$, Leandro Pisani ${ }^{2}$, Gustavo R. Cointry ${ }^{1}$, Ricardo F. Capozza ${ }^{1}$.

${ }^{1}$ Centro de Estudios de Metabolismo Fosfocálcico (CEMFoC). Facultad de Ciencias Médicas. Universidad Nacional de Rosario. Rosario; Argentina.

${ }^{2}$ Unidad de Estudios Biomecánicos Osteo-Musculares(UDEBOM). Centro Universitario de Atención. Docencia e Investigación (CUADI). Universidad del Gran Rosario (UGR). Rosario; Argentina.

${ }^{3}$ Centro de Mediciones Deportivas (CEMED). Secretaría de Asistencia Social y Salud Pública. Rosario; Argentina.
\end{abstract}

Autor por correspondencia: Gustavo Roberto Cointry — gcointry@gmail.com

Conflicto de intereses: no presenta.

\section{Resumen}

La OMS distingue osteopenias (simples pérdidas de masa ósea mineralizada) de osteoporosis (pérdidas con tendencia a la fractura) según la simple magnitud densitométrica del déficit mineral. En realidad, la resistencia de un hueso no depende de su masa mineralizada, sino de la combinación de la rigidez (resistencia a deformarse) y la tenacidad (resistencia a resquebrajarse) de su estructura, determinadas, a su vez, por la 'calidad mecánica' (rigidez y tenacidad) del tejido mineralizado y la 'calidad arquitectónica' de su distribución en cortezas y tramas trabeculares (diseño óseo). La resistencia ósea responde a un mecanismo retroalimentado ('mecanostato'), que adecua la distribución del tejido a su calidad, en función del sensado de las mini-deformaciones derivadas del uso, a cargo de los osteocitos. Ergo, la resistencia ósea no es una cuestión de masa, sino de 'estructura' y 'organización' servo-controladas. Entonces, la diferencia entre osteopenias y osteoporosis, independientemente de la masa densitométrica, debe interpretarse evaluando el impacto estructural de la variable interacción de dos determinantes independientes: 1. el entorno mecánico direccional del esqueleto (input del mecanostato), y 2. su entorno sistémico humoral, no direccional, cuyas alteraciones perturban el control biomecánico direccional '1'. El componente 'l' (desuso) debe tratarse fisiátricamente, mediante estímulos mecánicos específicamente direccionados. El componente ' 2 ' (metabólico) requiere drogas específicas, cuyos efectos sistémicos sobre osteocitos, osteoblastos formadores y osteoclastos destructores de hueso están fuertemente condicionados a la normalidad de (1). El éxito terapéutico dependerá de en qué medida se reconsidere a las osteoporosis, no como enfermedades de la masa, sino del diseño óseo.

Palabras clave: Osteopenia. Osteoporosis. Estructura ósea. Resistencia ósea. Biomecánica ósea. Mecanostato. 


\section{Abstract}

The WHO differentiates between osteopenias (simple losses of mineralized bone mass) and osteoporoses (losses with increased fracture risk) based on just the amount of the remaining, densitometrically - assessed bone mineral mass. To note, the strength of a bone does not depend on its mineralized mass but on the combination of its stiffness (resistance to deformation) and toughness (resistance to split). These 'structural' properties result from the quality (stiffness, toughness) and spatial distribution (cortical/trabecular design) of bone tissue. The whole-bone strength is controlled by a feedback mechanism ('mechanostat') that adapts tissue distribution to tissue quality as a function of the usage-derived bone strains sensed by osteocytes. Therefore, bone strength does not reflect a metabolically accumulated mass but a biomechanically servo-controlled structure oriented by a well-established organization. Thus, the difference between osteopenias and osteoporoses, regardless of bone mineral data, must be interpreted by assessing the structural impact of the variable interaction of two independent determinants, namely, 1. The directional ('vectorial') mechanical environment of the skeleton (mechanostat input), and 2. The non-directional ('systemic') endocrine-metabolic environment, which privileges the mineral homeostasis control (essential to bone health) over bone structural integrity, thus tending rather to disturb than co-adjuvate the directional control of bone strength by changing the mechanostat setpoint. The mechanical component (1) must be treated by a directionally specific mechanical stimulation of bones. The metabolic component (2) requires drugs whose systemic effects are strongly conditioned to (1). Treatment success will depend largely on reconsidering osteoporoses as diseases of bone design rather than bone mass.

Keywords: Osteopenia. Osteoporosis. Bone structure. Bone strength. Bone biomechanics. Mechanostat.

\section{Introducción}

El avance del conocimiento sobre estructura y biomecánica ósea en los últimos 30 años desafía la interpretación, el diagnóstico y el tratamiento de las osteopatías fragilizantes, especialmente las osteoporosis. Las nuevas nociones sobre la compleja relación entre la estructura de los huesos y la organización de los mecanismos que la determinan, sugieren el inquietante planteo filogenético: Si el huesoeslarespuesta, ¿cuálfuelapregunta?(1). Elcorrespondienteparadigmareplantealadeterminación y el control biológico de la direccionalidad preferencial (anisotropía) que invariablemente caracteriza la resistencia de la estructura de todos los huesos, y valoriza sus relaciones con el entorno mecánico del esqueleto, especialmente respecto de las interrelaciones musculoesqueléticas (2-4). Esta breve revisión elaborativa pretende 1. definir nuestra posición, y nuestra contribución al desarrollo de las nuevas concepciones, con argumentos originales publicados (5); y 2. orientar al osteólogo clínico sobre sus incumbencias diagnósticas y terapéuticas, con referencias complementarias a trabajos de otros autores y a textos comprehensivos sencillos, clásicos y propios.

\section{El fundamento biológico}

La producción de tejido óseo mineralizado tiene lugar a partir del colágeno, una proteína estructural (es decir, con propiedades resistivas espacialmente direccionadas) producida por los osteoblastos, y de su auto-ensamble en microestructuras más complejas, también direccionales, como lamelas y osteonas (6). Tanto el arreglo espacial de estas microestructuras como su ulterior calcificación, resultan de procesos fisicoquímicos esencialmente automáticos, orientados por las correspondientes fuerzas de interacción intermoleculares. Además, la ‘construcción' particular, también direccional, de cada hueso utilizando ese tejido, procede en general respetando la predeterminación morfogenética de su forma primaria; es decir, también cursa en forma predominantemente automática.

Esto podría sugerir, erróneamente, que la direccionalidad resistiva de cada hueso, y hasta la del esqueleto entero, están genética y fisicoquímicamente determinadas en forma espontánea, sin otro tipo de interacción. Así, podría creerse que el crecimiento y el desarrollo óseos estarían determinados por los procesos metabólicos proveedores de los materiales de construcción, regulados hormonalmente en forma integral, que son de naturaleza 'sistémica'; es decir, 'no-direccional', con efectos idénticos en todas partes, sin participación de otros factores. Esto, sin embargo, sería tan ingenuo como pensar que una planta nace y crece normalmente 'a golpes de sol y de agua', tomando de la tierra lo necesario para orientar su crecimiento y sostener su estructura, e ignorando la influencia mecánica de la dirección y 
la magnitud de la carga de las ramas y de la fuerza del viento. En realidad, estos y otros factores físicos fundamentales determinan normalmente la direccionalidad de todas las estructuras biológicas de sostén a niveles de complejidad más altos que el molecular, participando de mecanismos que distan de cursar en forma espontánea, o de ordenarse espacialmente en forma automática (7).

Para un hueso, lo mismo que para una planta, los procesos que determinan su capacidad de sostén, tanto durante el desarrollo como en la adultez, están orientados no sólo morfogenética y fisicoquímicamente, sino también por factores biomecánicos (tracciones/compresiones derivadas del ambiente y del uso) que tienen una direccionalidad propia, coincidente o no con la de los demás procesos, y cuya influencia puede variar para distintos puntos de su estructura $(7,8)$. Por eso, la resistencia mecánica de un hueso se expresa siempre en forma anisotrópica; es decir, 'con diferente intensidad en distintas direcciones'.

Examinada desde la Biología de Sistemas $(9,10)$, esta determinación direccional de la aptitud mecánica de los huesos resulta de la combinación de dos procesos biológicos que cursan a dos niveles de complejidad biológica diferentes: el tisular, relativo a la microestructura del tejido mineralizado, y el orgánico, relativo a la macroestructura del hueso entero (11-13). Como en cada uno de ellos la direccionalidad juega distinto, los analizaremos por separado:

- A nivel tisular, las macromoléculas de colágeno son producidas por los osteoblastos, originalmente ubicados en sitios morfogenéticamente predeterminados, siguiendo o no un patrón cartilaginoso previo (osificación endocondral o membranosa, respectivamente), y luego orientados por los procesos que se discuten más abajo. Las macromoléculas de colágeno se agrupan siempre en haces de fibrillas (fibras), y éstas en manojos, dispuestos en capas paralelas, como cigarros en cigarrera. Un número variable de estas capas se apilan una sobre otra, en forma similar a la madera terciada, con distintas orientaciones de las fibras de una a la otra, constituyendo las llamadas lamelas. Las lamelas, a su vez, se superponen unas sobre otras como capas de cebolla, formando estructuras compactas compuestas, que pueden disponerse en forma paralela (cortezas óseas, que pueden luego ser remodeladas a tramas trabeculares) o bien concéntrica (sistemas de Havers intracorticales), llamadas osteonas $(6,14)$. La mineralización de las osteonas completa la constitución de la 'matriz ósea mineralizada', en tanto actúan también los factores mecánicos locales referidos antes (15). Esta complejidad microestructural altamente direccionada del tejido mineralizado, que le confiere una importante anisotropía, se manifiesta en dos modalidades de 'resistencia' distintas y complementarias:

1. la resistencia a la deformación por el soporte de cargas (rigidez del tejido), que podría determinar resquebrajaduras en su seno, y

2. la resistencia a la formación y/o el progreso de esas resquebrajaduras (tenacidad del tejido), que limita la separación física del hueso en fragmentos (11-13).

Se puede proponer, groseramente, la expresión:

‘Calidad mecánica’ (resistencia) del tejido = Rigidez específica del tejido + Tenacidad específica del tejido.

Surge así la ineludible direccionalidad de las tres propiedades tisulares óseas: rigidez, tenacidad, y resistencia, con su dependencia biomecánica explicitada arriba.

- El nivel orgánico comprende la distribución espacial del tejido mineralizado, por encima de su direccionalidad intrínseca, en arreglos (macro)estructurales (apreciables a simple vista) (7) que sólo pueden respetar uno de dos patrones característicos: arreglos corticales 'sólidos', llamados 'cortezas', y arreglos trabeculares 'esponjosos', llamados 'tramas'. La microestructura del tejido en ambos arreglos es similar, porque el hueso trabecular generalmente constituye el residuo de la eliminación mecánicamente inducida de un hueso preexistente más compacto. Pero, obviamente, tanto tramas como cortezas conllevan su propia direccionalidad, por encima de la direccionalidad del tejido que las constituye. Este segundo nivel de complejidad estructural óseo (cortical/trabecular) le confiere a cada hueso una doble anisotropía, por integración de 1. la direccionalidad intrínseca, fisicoquímica, del tejido (nivel tisular) y 2. la direccionalidad morfogenética/biomecánica de las tramas y cortezas (nivel orgánico) (11). Decimos 'morfogenética/biomecánica', porque la direccionalidad 
de tramas y cortezas, por encima de su determinación genéticamente programada, es constantemente modificada por una permanente redistribución del tejido en función del uso mecánico del hueso, según se detalla más abajo. Esto es lo que determina, en forma excluyente, la direccionalidad específica de la función del hueso entero como estructura de sostén ('anisotropía del hueso'), y con ella, su resistencia a la fractura. Se pueden proponer entonces, groseramente (11-13), las expresiones:

$$
\begin{gathered}
\text { Rigidez y tenacidad del hueso }=\text { Rigidez y tenacidad del TOM }+ \text { Distribución espacial del TOM } \\
\text { Calidad mecánica' del hueso }=\text { 'Calidad mecánica' del TOM }+ \text { 'Calidad arquitectónica' de la } \\
\text { distribución }
\end{gathered}
$$

\begin{tabular}{|c|c|}
\hline sea' & $\begin{array}{c}=\quad \text { ‘Calidad del tejido’ } \\
\text { (Resistencia a la fractura) }\end{array}$ \\
\hline
\end{tabular}

Además de alertar sobre el frecuente uso inadecuado de la expresión 'calidad ósea', que confunde las tres 'calidades' expuestas, este esquema define las correspondientes propiedades mecánicas (direccionales) de cualquier hueso, correlativas de esas tres 'calidades':

$$
\text { Propiedades 'estructurales' = Propiedades 'materiales' + Propiedades 'geométricas' }
$$

Aunque no resulte intuitivo aceptarlo, la masa de mineral contenida en el tejido que forma un hueso (referida a veces incorrectamente como 'masa ósea', a secas), por ser una variable no-direccional, no resulta per se un determinante relevante de su resistencia. La masa de tejido solamente aporta el imprescindible sustrato material ('alguna masa' debe haber...) para la manifestación de esa resistencia, que antes dijimos que depende únicamente de los dos factores primordiales y excluyentes (ambos direccionales) referidos: calidad mecánica del tejido, y calidad arquitectónica del diseño trabecular, cortical e integral del hueso. 
A.

LA DIRECCIONALIDAD ORGANIZA A LA MASA

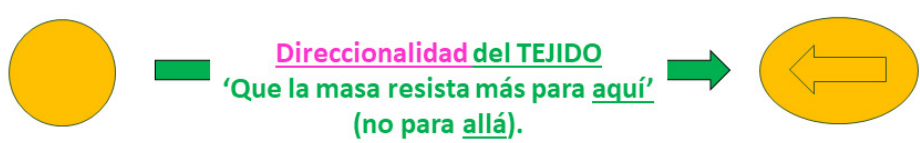

Automática (físico-química)
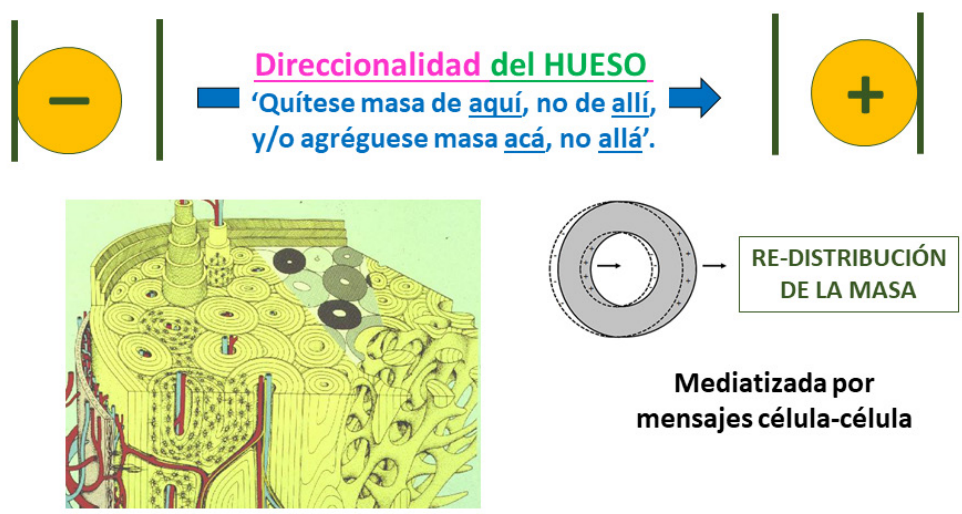

Mediatizada por mensajes célula-célula

B.

\section{Determinación biológica de las propiedades materiales, geométricas $y$ estructurales óseas}
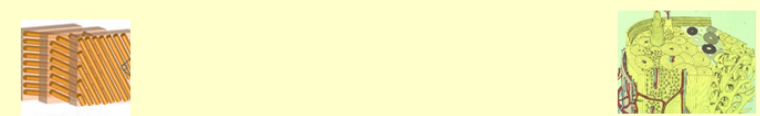

CALIDAD Y ORIENTACIÓN DEL COLÁGENO

MICROPOROS MINERALIZACIÓN

OTROS FACTORES CRISTALINIDAD

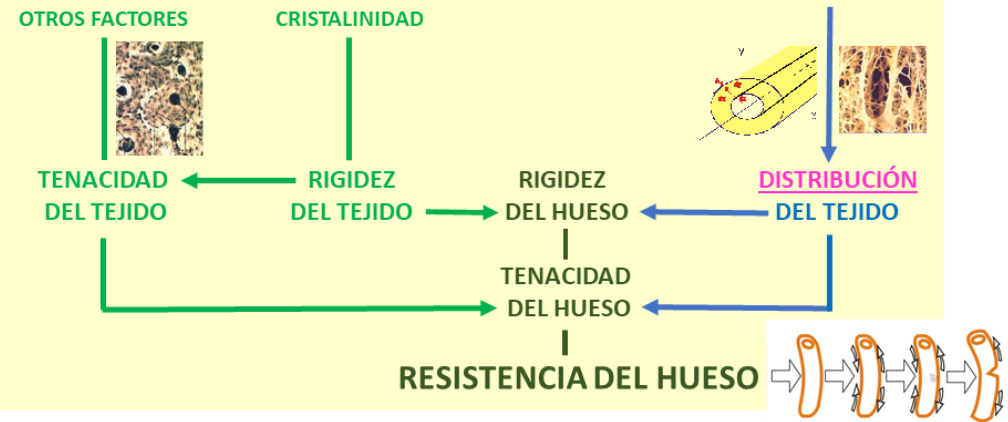

Adaptado de Ferretti, Mechanical properties of bones, Elsevier, 1996

Figura 1. (a) Representación esquemática de los dos niveles de complejidad biológica a los cuales se expresa la direccionalidad (anisotropía) estructural ósea: el tisular (arriba) y el orgánico (abajo). El nivel tisular comprende las fibras colágenas, arregladas en lamelas y osteonas y mineralizadas, con la consiguiente orientación espacial de sus elementos, que resulta, primariamente, de las correspondientes interacciones intermoleculares automáticas; y secundariamente, de las tracciones producidas por el uso mecánico del hueso. El nivel orgánico comprende la determinación de los sitios de formación y/o destrucción de ese tejido conforme los requerimientos mecánicos del entorno del esqueleto, según las únicas dos modalidades de acción posibles: la modelación (producción y/o destrucción aisladas), que modifica el diseño trabecular o cortical, y la remodelación (destrucción y reposición total o parcial del tejido, secuencialmente acopladas), que puede adelgazar cortezas y tramas, y también reducir la tenacidad del tejido cortical por exceso de porosidad. (b) Esquema descriptivo de la integración de la 'calidad mecánica' (rigidez + tenacidad, específicas) del tejido óseo mineralizado (izquierda) con la 'calidad arquitectónica' de su distribución en el espacio en cortezas y tramas trabeculares (diseño; derecha) para determinar la 'calidad estructural' (rigidez + tenacidad = resistencia) del hueso entero (centro-abajo). 
La resistencia a la fractura del hueso-órgano está fuertemente determinada por factores mecánicos externos (Figura 1-a), que operan desde el mismo momento de la generación del núcleo de osificación de cada hueso móvil, y lo hacen de un modo muy distinto a nivel de complejidad tisular (microestructura anisotrópica del tejido) que a nivel orgánico (macroestructura anisotrópica del hueso).

- A nivel tisular: La anisotropía de la microestructura del tejido mineralizado (Figura 1-a, arriba), es una propiedad que varía poco intrínsecamente desde la época de los dinosaurios (6), y puede afectarse, aunque sólo durante el proceso de formación ósea, por la direccionalidad de las tracciones/compresiones que naturalmente sufre el hueso desde su constitución como tal, según se refirió antes $(15,16)$. Después de mineralizado el tejido, su direccionalidad intrínseca ya no puede modificarse hasta su ulterior remodelación, con similar o distinta orientación de las fibras del tejido repuesto.

- A nivel orgánico: La anisotropía de la macroestructura del hueso (Figura 1-a, centro-abajo), en cambio, puede variar normalmente mucho, por distintos mecanismos que los que afectan al tejido, que comprenden los dos únicos procesos que pueden cambiar el diseño de la estructura de tramas y cortezas (17): la modelación (18) (formación y/o destrucción 'no acopladas' de tejido mineralizado en distintos puntos del hueso) y la remodelación (19) (destrucción y ulterior reposición total o parcial del tejido, 'acopladas' en un mismo punto del hueso, que cursan sobre la superficie de las trabéculas - lagunas de Howship- o en el seno del cortical — sistemas de Havers-), que también puede modificar la calidad tisular cortical aumentando su porosidad (20). Es así como las macroestructuras de los huesos (es decir: las propiedades geométricas que configuran su diseño) pueden diferir significativamente dentro de un mismo hueso, o de uno a otro, tanto dentro del mismo individuo como entre individuos de una misma especie, y entre especies diferentes. La determinación de la resistencia de cualquier hueso puede interpretarse conforme esta concepción (Figura 1-b), según se detalla más abajo. La organización del proceso de producción de estas variaciones geométricas comprende el comportamiento integrado y mecánicamente orientado de osteocitos, osteoclastos y osteoblastos, según sigue (21) (Figura 2-a): 
A.

\section{EL MECANOSTATO ÓSEO}

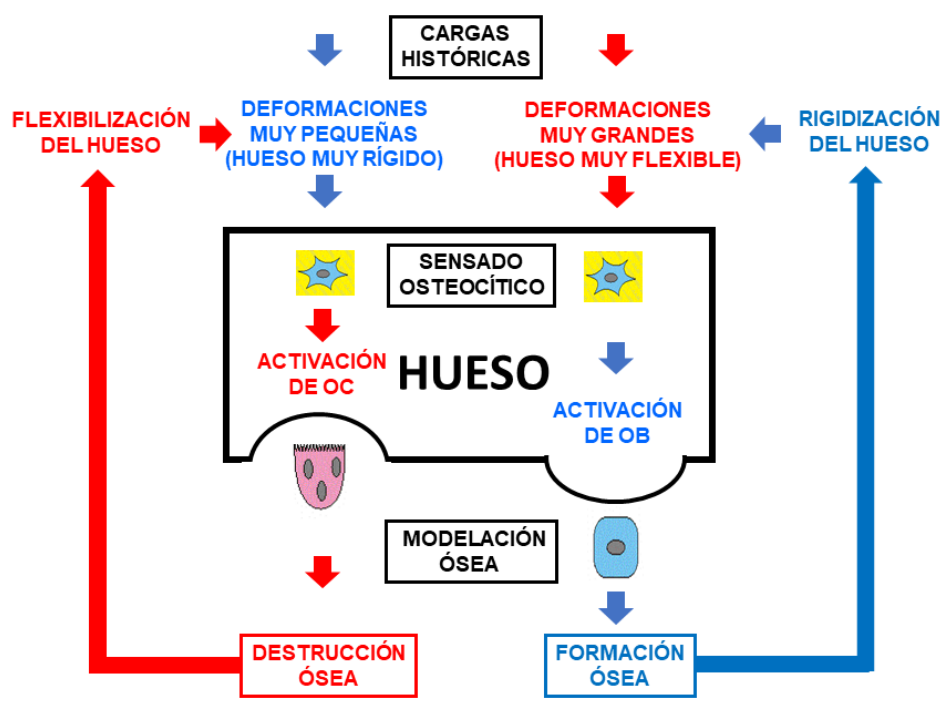

B.

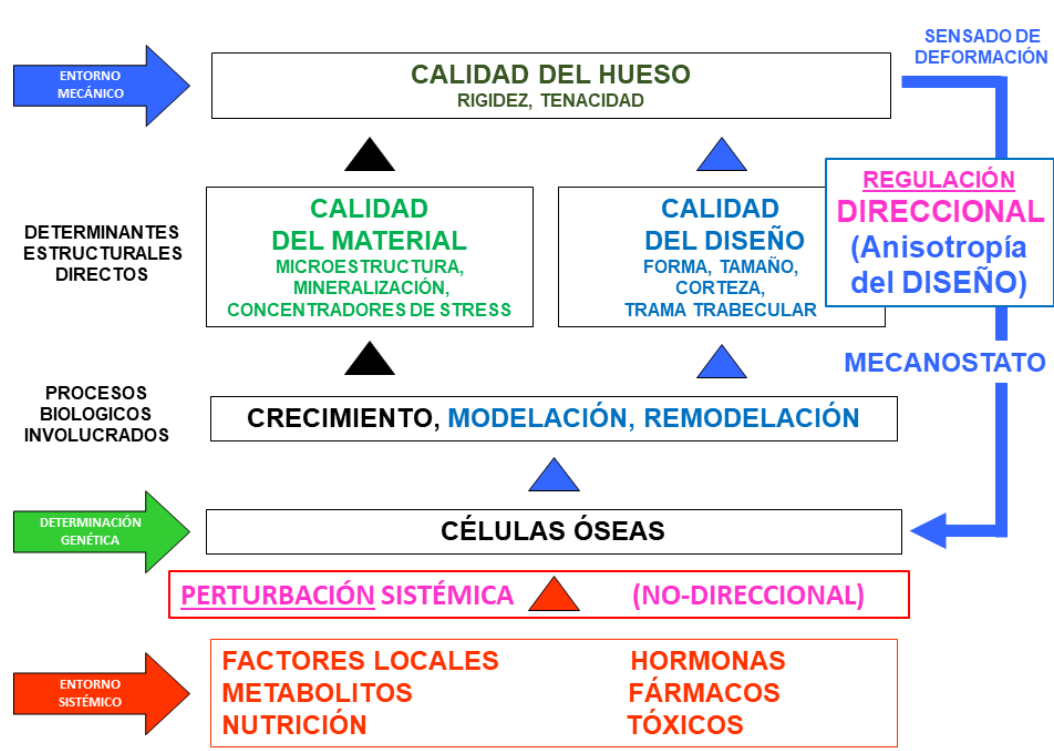

Figura 2. (a) Esquema que representa el mecanismo regulatorio retroalimentado (mecanostato) que controla la rigidez de la estructura ósea. Los osteocitos (células estrelladas) sensan las deformaciones tisulares provocadas por el uso del hueso y detectan direccionalmente 'señales de error' indicativas de una rigidez indebidamente alta o baja. En el primer caso, los osteocitos envían mensajes que activan a los osteoclastos (OC) vecinos (sistema 'RANK—RANK—L') para remover tejido mineralizado; y en el segundo, activan los osteoblastos (OB) cercanos (sistema 'Sost, esclerostina/anti—esclerostina') para depositar tejido nuevo en el sitio. El resultado es un equilibrio estructural que mantiene constante la rigidez estructural del hueso integrado a nivel de órgano; una propiedad muy cercana a la resistencia a la fractura, que es la única que se controla en los huesos de todos los vertebrados. (b) Representación funcional del mecanostato en 'pisos' de organización biológica. Cada nivel constituye una propiedad, un proceso o una estructura representados en forma autocontenida (todos los determinantes de su concepción están incluidos, y no se concibe otro factor interviniente que no esté contemplado). Cada nivel superior depende exclusivamente del nivel inferior inmediato, en forma solamente ascendente: la 'calidad del hueso' (resistencia a la fractura) depende de sus dos determinantes excluyentes: la 'calidad del tejido' y la 'calidad del diseño', que sólo pueden modificarse por el crecimiento, la modelación y/o la remodelación, que son procesos gobernados por células, obviamente sujetos a determinación genética. Las flechas en negro describen las relaciones que determinan la anisotropía (direccionalidad microestructural) del tejido óseo, sin mecanismo regulatorio conocido. Las flechas azules destacan la participación del mecanostato en la regulación retroalimentada de las propiedades mecánicas del hueso entero (direccionalidad estructural -'calidad del hueso', o 'resistencia ósea'). La flecha roja inferior indica la interferencia de todos los factores sistémicos osteoactivos (hormonas, metabolitos, drogas, tóxicos, etc.) que ejercen efectos generales, 'no-direccionales' (todo estimulado, o bien todo inhibido, en todas partes por igual), que, independientemente de su necesidad para el normal crecimiento y funcionamiento de los huesos, perturban en todos los casos el control direccional natural de la resistencia ósea por el mecanostato. 
Los osteocitos, naturalmente inmersos en el seno del tejido mineralizado y conectados entre sí por sus prolongaciones citoplasmáticas, 'sensan' las pequeñas deformaciones de su habitat producidas en cualquier sentido por el uso mecánico del hueso, mediante un proceso biofísico, por la producción de deslizamientos inter-capa de sus membranas celulares. De esta manera, los osteocitos cuantifican la dirección y la magnitud de las variaciones producidas en la longitud de reposo del hueso, con participación de su citoesqueleto (22). Así es como los osteocitos pueden detectar 'señales de error' de deformación, derivadas de la falta o del exceso de rigidez de su estructura, y determinar su direccionalidad. La forma de los osteocitos, variable en distintas regiones del esqueleto, contribuye a optimizar este sensado $(23,24)$. Esto les permite 'distinguir' cuándo la historia reciente de esas deformaciones es demasiado alta (sobreuso, o falta de tejido mineralizado - baja rigidez) o demasiado baja (desuso, o exceso de tejido - alta rigidez) en sitios puntuales, así como detectar su direccionalidad (25). En respuesta a esas 'señales de error', con participación de modulaciones epigenéticas específicas (26), los osteocitos envían mediadores celulares bioquímicos direccionados a los osteoblastos u osteoclastos vecinos (que se encuentran fuera del tejido duro). Siguiendo este mecanismo, los estímulos mecánicos determinan una suerte de modelación orientada (18,19): en el primer caso, la formación osteoblástica de nuevo tejido en el sitio en cuestión, con participación de sistemas moleculares como el de 'esclerostina/anti-esclerostina' (27); y en el segundo, la destrucción osteoclástica del tejido preexistente, sin reemplazo ulterior, con participación de sistemas moleculares como el 'RANK—RANK/L' (28). Nótese la cooperación biofísico-bioquímica que caracteriza al proceso de transducción de la energía que deforma al hueso en la producción de estímulos/inhibiciones celulares direccionados que adecuan su diseño a su entorno mecánico (29). Curiosamente, la modificación de la anisotropía del hueso entero es más rápida que la del tejido. La remodelación del tejido es un proceso puntual que lleva varios meses en cada sitio; en tanto la formación modelatoria de hueso nuevo en amplias capas es cuestión de pocas semanas; y su destrucción, de pocos meses (17). De todos modos, la direccionalidad de la liberación y el tipo de los mediadores osteocíticos involucrados determina la direccionalidad y el tipo de la respuesta modelatoria del sistema, que es la más importante para la adecuación del diseño, y con él, el comportamiento direccional (la anisotropía) del hueso entero (Figura 2-b).

De esta manera queda constituido un sistema regulatorio retroalimentado, llamado 'mecanostato óseo' por Frost (8), que controla direccionalmente la deformabilidad estructural del hueso entero. Esta concepción mejora substancialmente el vago enunciado de la antigua 'Ley de Wolff': 'Todo cambio en la forma y/o en la función de un hueso se sigue de cambios definidos en su arquitectura interna y/o en su conformación externa, de acuerdo con leyes matemáticas' (30). En efecto, Wolff no propuso ninguna clase de relación determinante de ese comportamiento, ni definió las variables involucradas, ni propuso los sensores y efectores del proceso involucrado.

Según Frost, la constante redistribución mecánicamente orientada del tejido mineralizado que provee el mecanostato tiende a procurar y mantener un factor de seguridad de entre 6 y 10 entre la máxima carga o deformación que puede resistir el hueso antes de fracturarse en una determinada dirección, y la carga o la deformación soportadas durante esfuerzos fisiológicos máximos efectuados en la misma dirección. De esta manera, los huesos adaptan su diseño a las modalidades de uso propias de su portador (31-34). Notablemente, cada hueso se comporta como un imaginario 'edificio inteligente', capaz de quitar material de donde sobra y/o agregarlo donde falta, cada vez que la historia de deformaciones que se detecta indique la necesidad de hacerlo. Esta situación es especialmente evidente cuando se analizan los efectos estructurales óseos de la actividad física (35-40).

Estas relaciones no son fáciles de estudiar. Nosotros hemos demostrado en forma original que las propiedades materiales y geométricas óseas tienden a complementarse, variando en forma recíproca, en función de las cargas inducidas por el uso mecánico del hueso por su portador. Estas relaciones respetan una forma negativa hiperbólica, que hemos descripto originalmente como curvas de "distribución/calidad" (41-44) (Figura 3-a). Las curvas de distribución/calidad describen el comportamiento de indicadores geométricos no-invasivos (tomográficos) de la distribución del tejido cortical de la diáfisis de un hueso largo, en función de la mayor o menor docilidad del tejido mineralizado a deformarse. Generalmente, como indicador de ‘distribución' (y) se emplea uno de los 'momentos de inercia' seccionales de las secciones diafisarias de huesos largos, relativo a un eje de deformación seleccionado, que cuantifica en qué medida el tejido cortical ha sido distribuido por el mecanostato en la sección del hueso en relación con algún eje de referencia para flexión o torsión; y como indicador de 'calidad' ( $\mathrm{x}$ ) se utiliza un correlato de la rigidez específica del tejido duro, que es la densidad mineral volumétrica del cortical (45). 


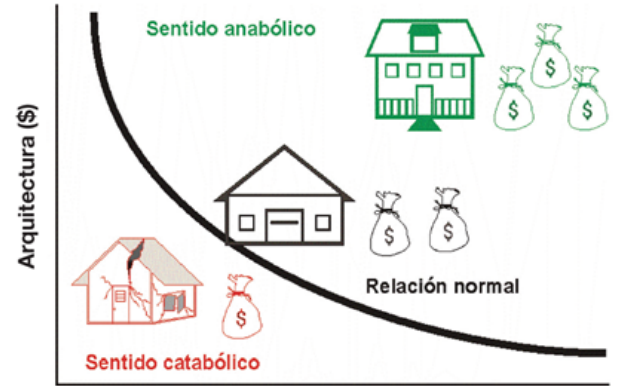

Calidad del material (\$)

a

Concepto de "distribución/calidad" (d/c). La determinación biológica entre la calidad (rigidez) del teidid control de una relacion negativa (hiperbolica) (v). similar a la gue existe entre el costo de la calidad de los materiales $(x)$ y del arquitecto contratado (y) para construir una casa. ${ }^{12}$

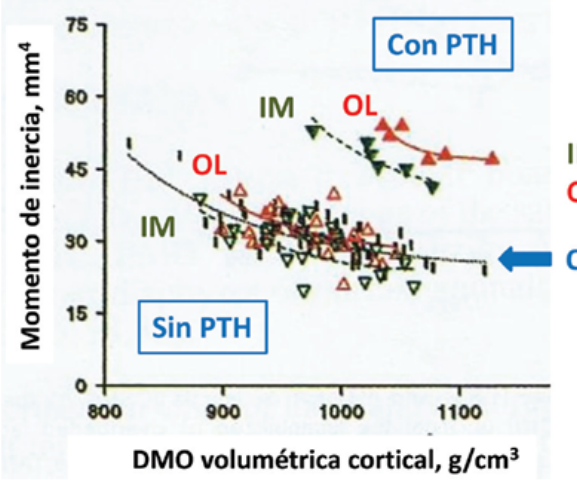

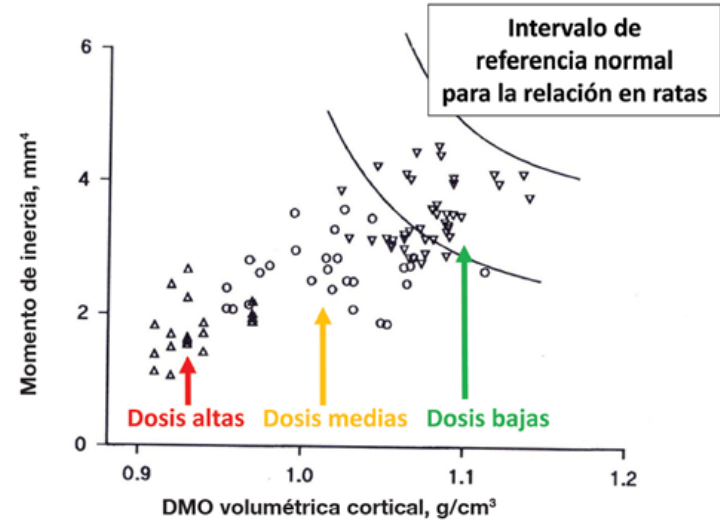

b

Las mismas relaciones de "distribución/calidad", en fémures de ratas tratadas con distintas dosis de dexametasona, con referencia a ratas sin tratar, describen el efecto catabólico dosis-dependiente del tratamiento. ${ }^{2 \mathrm{~B}}$

Figura 3. (a) Representación didáctica de una relación de ‘distribución/calidad' como la que proponemos para los huesos, asimilada a la que gobierna la dependencia recíproca de los gastos derivados de la calidad de los materiales adquiridos y de la idoneidad del arquitecto contratado para la construcción de una casa. La curva expresa la relación normal entre esos gastos, delimitando la gráfica en una zona superior-derecha (gastos excesivos, calidad superior innecesaria - que biológicamente podría considerarse 'anabólica'), y una inferior -izquierda (gastos reducidos, peligro de derrumbe del edificio - que podría considerarse 'catabólica'). (b) En Osteología Experimental, la misma relación describe el comportamiento asociado de la eficiencia de distribución del tejido mineralizado por el mecanostato (expresada por un 'momento de inercia' seccional de un hueso largo; y) en función de su rigidez intrínseca (expresada por su DMO volumétrica; x). La gráfica muestra los efectos 'catabólicos' producidos sobre la relación observada en huesos de ratas tratadas con dosis bajas, medias o altas de dexametasona, comparados con la relación normal observada en un grupo control de referencia, no tratado. (c) La misma relación, representada para huesos de ratas tratadas (arriba) o no (abajo) con PTH anabólica, que fueron inmovilizados (IM) o sobrecargados (OL) durante el tratamiento, contra un control normal sin tratar. Se observa el efecto ‘anabólico’ del tratamiento con la hormona, y su potenciación agonística por la actividad física (primera referencia publicada de la potenciación de un efecto anabólico óseo por el entorno mecánico del esqueleto).

La altura gráfica (la 'ordenada') de una curva de distribución/calidad expresa la eficiencia del mecanostato para optimizar el diseño seccional del hueso para resistir flexión o torsión, para un mismo nivel de rigidez del tejido. En consecuencia, las curvas son sensibles al uso mecánico del hueso, y a la administración de tratamientos que modifiquen la eficiencia del sensado osteocítico, o la actividad formadora o destructora de los osteoblastos y osteoclastos vecinos. Por tanto, las curvas de distribución/calidad pueden, además de evaluar el estado funcional del mecanostato, cuantificar los cambios inducidos por distintos tratamientos sobre la eficiencia mecánica de la disposición del tejido cortical diafisario. Y también pueden calificar la participación del mecanostato en la conformación esquelética de especies filogenéticamente vecinas con diferente morfología corporal $(42,46,47)$.

Aplicando experimentalmente nuestras curvas de distribución/calidad (41), complementadas por test destructivos de huesos de ratas, hemos sido pioneros en describir

1. los efectos biomecánicos geométricos de tratamientos 'sistémicos' con 5 bisfosfonatos (48-55) (incluyendo la primera revisión publicada de sus efectos biomecánicos (56), y una Familia Internacional de Patentes sobre el Olpadronato (57)), 4 glucocorticoides (Figura 3-b) (49,58-61), PTH natural y 'anabólica' $(62,63)$, varios calciferoles $(64,65)$ (comprendiendo el primer bioensayo de actividad calciferólica publicado basado en efectos biomecánicos 
óseos), calcitonina (51), hGH recombinante (66), ranelato de estroncio (67) y aluminio (68), e ingestas de Ca y proteínas (62,69,70); y

2. los efectos direccionales potenciadores de la actividad física sobre los de un tratamiento osteoactivo (primera referencia de ese tipo de acción en la literatura; (Figura 3-c) (63), demostrando en todos los casos su relación con el estado funcional del mecanostato.

También analizamos la estructura ósea in vivo con criterio biomecánico en mujeres osteoporóticas sanas o fracturadas, tratadas o no con PTH recombinante (71-73), en pacientes celíacos (74), en niños tiroidectomizados por carcinoma tiroideo luego del accidente de Chernobyl (75), en patologías mitocondriales, y en la osteogénesis imperfecta.

Esto nos permitió proponer novedosas razones biomecánicas para explicar la prevención sólo transitoria de fracturas que proveen los tratamientos corrientes, que sólo incrementan la masa de tejido mineralizado erráticamente (en forma sistémica) en puntos esqueléticos que pueden o no ser relevantes para ese fin. Esos efectos desaparecen al suspender los tratamientos $(76,77)$, en forma rebelde a la administración ulterior de bisfosfonatos como protectores del tejido contra su remoción natural (78). Esto sucede porque el mecanostato da rápida cuenta de todo el tejido excesivo, modulado solamente por el grado de actividad del paciente $(19,80)$. El éxito de tales tratamientos dependería pues, de la correcta estimulación direccional de los huesos-blanco durante su curso, un aspecto que corrientemente nadie está teniendo en cuenta.

Hemos demostrado, además, que algunos huesos particulares, como el peroné humano, no responden en forma 'canónica' a la inmovilización prolongada o al entrenamiento crónico (en carrera o fútbol) $(36,40,81,82)$, como sería predecible por la Ley de Wolff o la Teoría de la Elasticidad (83). Los comportamientos observados remedan lo que ocurre naturalmente en otros bípedos y en cuadrúpedos superiores, en quienes la estructura cortical del peroné se adecua a las modalidades de uso del pie determinadas por el ambiente ecológico de cada especie, por encima de sus vecindades filogenéticas (84-86). Ese comportamiento sugiere, llamativamente, que la función regulatoria de la rigidez estructural ejercida por el mecanostato se extendería también a otras propiedades de los huesos, que presentan altas connotaciones selectivas (el diferente uso del pie al correr es vital para predadores y presas), sean o no relevantes para la determinación de la resistencia a la fractura (87). Hemos propuesto que esta propiedad tal vez comprenda la regulación epigenética de alelos ancestrales del genoma humano, filogenéticamente responsables de esos comportamientos (25).

Así, desde el punto de vista práctico, la adaptación biomecánica ósea siempre proveería respuestas estructurales beneficiosas a los estímulosmecánicosrelevantes para la vida normal. Y todo ocurriría como si, en vez de reglas matemáticas de optimización para la estructura ósea, sólo existiera un proceso biológico que adaptara esa estructura a las demandas mecánicas adecuadas para la supervivencia $(88,89)$. Estas atractivas observaciones apoyan la necesidad de investigar los efectos biomecánicos de entrenamientos direccionalmente orientados a reforzar la estructura ósea en sitios esqueléticos propensos a fracturarse (especialmente en casos de osteoporosis), específicamente en las direcciones seleccionadas, antes que en las naturalmente desafiadas por el comportamiento cotidiano del esqueleto.

\section{El correlato clínico-terapéutico}

Sintetizando todo lo anterior [11-13], podemos decir que:

La 'calidad estructural' de un hueso (su resistencia a la fractura) depende, además de la morfogénesis, de las orientaciones direccionales derivadas del uso mecánico determinadas a dos niveles distintos de complejidad: tejido y órgano.

De hecho, la resistencia de cualquier sólido depende de la calidad mecánica microestructural del material que lo constituye (en el hueso, el tejido mineralizado), y de la calidad arquitectónica de la orientación de su distribución en el espacio, o diseño (en el hueso, las tramas y cortezas - Figura 1-b) (7). Además, en los huesos, el mecanostato controla y optimiza permanentemente la calidad mecánica de su macroestructura en forma estrictamente direccional. Estas características resultan clínicamente interesantes, porque el mecanostato puede afectarse por diversos factores, con variable impacto sobre la resistencia ósea a la fractura, según sigue.

El mecanostato (Figura 2) podría regular per se la rigidez estructural, única variable controlada en los huesos de todos los vertebrados (33), que es una propiedad muy cercana a la resistencia a la 
fractura (11-13). Sin embargo, el funcionamiento del mecanostato puede alterarse por la interacción de los factores humorales (sistémicos, no-direccionales) reguladores del equilibrio mineral del organismo, que comparten con él sus efectores osteoblásticos y osteoclásticos para el control vital de la calcemia, la fosfatemia y la magnesemia (Figura 2-b) (32,34). Este control homeostático ancestral es filogenéticamente mucho más antiguo que el advenimiento y la evolución de los esqueletos, con su mecanostato direccional incorporado. Por tanto, el mantenimiento sistémico de su normalidad es más 'vital' que el mantenimiento 'direccional' de la integridad esquelética de cada individuo. De hecho, en Biología, el sistema homeostático que 'llega primero' y resulta imprescindible para la subsistencia según la Selección Natural, impone las condiciones propias de su regulación a todos los mecanismos que se desarrollen más tarde (9).

Por esta razón, cada vez que es necesario aportar $\mathrm{Ca}$, P o Mg al medio interno, quien 'paga las cuentas materiales' de la reposición del equilibrio es el esqueleto, una fuente inagotable de esos elementos, pero también sensible a la necesidad de su presencia en sitios mecánicamente relevantes. Por otra parte, no existe ningún mecanismo conocido que luego le reintegre a cada hueso el tejido destruido para obtener el material 'aportado', en forma direccionada hacia los sitios afectados. Esto determina, obviamente, la producción de defectos erráticos de masa por efectos del entorno endocrino-metabólico del individuo, como ocurre en la menopausia (90). Si estos defectos afectaran significativamente la eficiencia mecánica del diseño del hueso, podrían, por su magnitud, superar la capacidad operativa del mecanostato para neutralizarlos. Lamentablemente, ningún agente 'sistémico' conocido, humoral ni genético, controla la masa, la formación, la destrucción, la modelación, la remodelación, ni la tasa de recambio óseos, ni siquiera la resistencia estructural misma, porque esas variables no se pueden medir biológicamente; $\mathrm{y}$ lo que no se puede medir no se puede regular (9). Y ni hablar de la posibilidad de que, aunque fuera factible, esa supuesta regulación pudiera cursar en forma direccional, 'focalizada' en los puntos estructuralmente críticos de los huesos por acción de esos agentes sistémicos. Esta es la causa de casi todas las osteopenias (y osteoporosis) conocidas (32,91).

En consecuencia, nuestros trabajos sobre el mecanostato apoyan la distinción etiopatogénica de tres clases de 'osteopatías fragilizantes' (32):

1. Primarias, en las cuales están afectadas las células sensoras o efectoras del sistema;

2. Por desuso, en las que está reducida su estimulación mecánica direccional (input), y

3. Secundarias, en las cuales las células y la estimulación están en orden, pero se encuentra desplazado su punto de referencia celular (setpoint) para la detección de las señales de error, o bien está alterado el trabajo de sus efectores blásticos o clásticos, por factores endocrinometabólicos.

Esto concierne, por extensión, a todas las osteopenias y osteoporosis. Por todo lo anterior, nos animamos a proponer las siguientes definiciones (32):

- Osteopenia: Déficit de tejido mineralizado dentro del hueso, con normalidad del remanente.

- Fragilidad ósea: Reducción de la resistencia ósea a la fractura, de cualquier naturaleza.

- Osteoporosis: Fragilidad ósea de origen osteopénico.

Estas concepciones difieren del concepto original de 'osteoporosis' propuesto por Lobstein en 1835 y por otros anatomopatólogos del Siglo XIX, que caracterizaban a este estado esquelético por la mera 'presencia de poros de mayor tamaño que lo habitual' en la estructura de los huesos. Y también superan, a nuestro entender, el alcance y la claridad de los desarrollos ulteriores de esos conceptos primitivos por la evolución de las tecnologías diagnósticas del estado esquelético.

El advenimiento de la Radiología permitió estimar aceptablemente el déficit de tejido mineralizado que caracterizaba a las 'osteoporosis', estableciéndose que podía detectárselo 'a partir de una pérdida de aproximadamente un 30\% de absorción' por los huesos. Surgieron así los conceptos de 'masa ósea mineralizada', con mayor correlato biofísico que el de 'poros', y de 'osteopenia', correspondiente a una reducción relativa de la masa de tejido mineralizado dentro del hueso. Además, para evitar toda confusión con otras osteopatías, fragilizantes o no, que también reducen la cantidad de tejido o la densidad mineral del hueso, quedó establecido que 'tanto las osteopenias como las osteoporosis se caracterizaban por la normalidad anatomopatológica del tejido óseo remanente' (una característica bastante difícil de establecer, hasta hoy). 
Desde hace cerca de medio siglo, la absorciometría de doble haz de rayos X ('densitometría ósea', DXA) permitió cuantificar, en imágenes coloreadas, el 'contenido mineral óseo' (CMO) y su correspondiente 'densidad mineral ósea' de proyección ('areal', DMO, expresada en g/cm2; no 'volumétrica', vDMO, expresada en $\mathrm{mg} / \mathrm{cm}^{3}$ ) del cuerpo entero y de regiones esqueléticas críticas como la columna lumbar, el fémur proximal y el radio distal. Esto permitió cuantificar con mayor precisión la 'falta de hueso dentro del hueso' en forma comparativa con valores de referencia, medios y de desvíos estándar, de muestras grandes de individuos jóvenes normales, calculándose los correspondientes ' $\mathrm{T}$-scores' (desvíos estándar) de diferencia entre los datos de DMO del individuo estudiado y las medias de referencia para cada región analizada. Quedaron así establecidos por la OMS (92) los diagnósticos 'cuantitativos' de osteopenia, cuando el T-score del individuo estudiado resultaba entre $-1.0 \mathrm{y}-2.5$, y de osteoporosis, cuando era igual o menor al valor de -2.5.

Llamativamente, este criterio dejó sentado, sin mayor correlato biomecánico de los datos,

- que el diagnóstico de 'osteoporosis' quedaba definido cuantitativamente, en forma antropométrica, por el grado de deterioro de la masa de mineral dentro de los huesos; y

- Que la mera presencia de 'osteoporosis' así diagnosticada, en términos de 'masa ósea', representaba per se un deterioro de la calidad mecánica ('fragilidad') de la estructura ósea que incrementaba proporcionalmente el riesgo de fractura del hueso estudiado.

En un primer momento esto pareció correcto, por resultar empíricamente congruente con la primitiva asociación reportada por Albright entre menopausia, 'osteoporosis' y fracturas, que podría controlarse mejorando el aporte de Ca (93). Sin embargo, y pese a que muchas correlaciones (espurias) verificaron esa relación años más tarde, y aun hasta hoy, esa concepción no dejaba de ofrecer flancos opinables:

1. Los pacientes fracturados con T-scores de DMO por encima o por debajo de -2.5 quedaron definidos como 'osteoporosis establecidas', un diagnóstico accesorio para el cual aún hoy se carece de correlato biomecánico.

2. Se observaron inconsistencias en las correlaciones reportadas entre valores de T-scores de DMO e incidencia de fracturas en ciertas condiciones de estudio.

3. Estas falencias son explicables, con sólo tener en cuenta, entre otras razones, que:

a. pequeñas estructuras conectivas, de mínima masa, pueden ser mecánicamente más relevantes que grandes masas de tejido con otras connotaciones mecánicas;

b. de nada valen el número, el grosor ni la 'densidad' trabecular, ni su aumento farmacológico, en tramas masivas pero pobremente conectadas.

c. las diáfisis de huesos largos con grandes diámetros pueden ser más resistentes en flexión o torsión que las de otros, con la misma masa mineral, pero más delgados y de paredes más gruesas (concepto del 'momento de inercia' (7)), cuya aDMO sería mayor.

d. la aDMO ignora, por un lado, el grado de porosidad y las resquebrajaduras corticaloes, ambos relevantes para la tenacidad ósea; y por otro, la calidad mecánica del tejido (incluyendo la mineralización misma) y la calidad arquitectónica del diseño del hueso, que son los dos determinantes excluyentes de su resistencia, y

e. laresistencia deun huesovaría muchocon la dirección delascargas, independientemente de su aDMO.

De todos modos, miles de extrapolaciones gratuitas del concepto metabólico de masa (de tejido mineralizado dentro del hueso) al concepto biomecánico de resistencia (del hueso estructuralmente integrado) fueron aceptadas libremente durante décadas por todas las publicaciones científicas, y por todos los especialistas, como un 'estándar de oro' para el diagnóstico de 'osteoporosis' (sic).

El Consenso Internacional de Hong Kong de 1993 (94) — que no puede decirse que fue unánime, ya que al menos uno de los presentes (el coautor JLF de este trabajo) no lo firmó (!) - estableció una nueva caracterización de la osteoporosis como una "reducción de la masa ósea mineralizada con desorganización de su microarquitectura (sic) y aumento de su fragilidad". Esta definición, pese a mejorar la de la OMS, porque al menos asoció la fragilidad al diagnóstico en forma concreta, presentaba todavía dos falencias importantes:

1. no aclaró suficientemente en qué consistía esa 'microarquitectura', que muchos asimilaron a la (macro)arquitectura de las tramas trabeculares como única alteración estructural propia de la osteoporosis, ignorando el deterioro cortical por adelgazamiento (un factor 
geométrico) y por exceso de remodelación haversiana (un factor 'material, tisular') como determinantes del riesgo; además,

2. ignoró toda relación del síndrome osteoporótico con el estado muscular del individuo (el conocido concepto de 'muscle-bone unit') (95) o con el entorno mecánico del esqueleto.

Un poco más allá fue la definición del NIH de 2001 (96), que despejó toda duda acerca del deterioro mecánico propio de las osteoporosis, al definirlas como 'compromisos de la resistencia ósea que predisponen al paciente a un mayor riesgo de fractura'. Claro que nadie advirtió, aún hasta hoy (ignoramos por qué), que esa caracterización, también aceptada en todo el mundo, aunque incongruente con la anterior, es absolutamente coincidente con la definición de una 'osteopatía fragilizante' cualquiera (!), sin especificar de cuál de las múltiples formas reconocidas (incluidas las osteoporosis) se trataría.

De cualquier modo, los nuevos criterios diagnósticos de osteoporosis, tanto del Consenso como del NIH, sugieren que se trataría de una fragilidad ósea osteopénica. Esta concepción trasciende el alcance diagnóstico de la DXA para osteoporosis basado en T-scores de DMO recomendado por la OMS (que está siendo progresivamente desechado). De hecho, como la DXA no captura ningún factor determinante de la calidad del tejido ni del diseño óseos, sólo puede detectar 'carencias de mineral dentro del hueso' (asumiendo una calidad normal del tejido, que tampoco es analizada), y no puede evaluar la 'fragilidad ósea'. Es decir, sólo puede diagnosticar osteopenias de distintos grados, y no osteoporosis (97-100).

Para determinar indicadores genuinos de la calidad del tejido y del diseño óseos, por encima del alcance de la DXA, deben emplearse tecnologías alternativas de tipo seccional, como la tomografía computada cuantitativa, en sus variantes 'axial' (aQCT) y (preferentemente) 'periférica', de campo pequeño y mejor resolución (pQCT) [101-105]. Estas técnicas pueden analizar separadamente los tejidos cortical y trabecular, y determinar

1. la DMO (volumétrica) cortical, que puede considerarse un indicador linealmente proporcional a la rigidez específica del tejido óseo (45), aunque no capture su direccionalidad, y

2. parámetros geométricos de huesos largos, como los 'momentos de inercia' (direccionales) (101-105), o el 'buckling ratio' (= diámetro óseo/espesor cortical), indicadores parciales de la calidad de su diseño arquitectónico para soportar flexión o torsión (7). La pQCT de alta resolución(HR-pQCT) puede, además, determinar indicadores de la eficiencia de las tramas trabeculares en radio y tibia distales, y simular su resistencia en condiciones prefijadas de deformación (106).

Sin embargo, todas esas tecnologías están aún lejos de ofrecer un diagnóstico biomecánico aceptable para cualquier osteopatía fragilizante. De todos modos, nosotros, empleando sólo pQCT (101-105) y test mecánicos destructivos a la flexión de huesos de pequeños animales, hemos demostrado que el producto entre la DMO volumétrica cortical y uno cualquiera de los momentos de inercia seccionales del centro de la diáfisis de un hueso largo, provee un índice direccional noinvasivo (el primero reportado) de resistencia ósea a la flexión o a la torsión (Bone Strength Index) $(107,108)$, extendido luego al llamado Stress—Strength Index $(109,110)$.

Un párrafo aparte merece el factor muscular, que configura las llamadas 'unidades músculohueso' (95) y las relaciones 'hueso/músculo'.

Hemos sido pioneros en demostrar que el uso de la fuerza muscular regional es el componente independiente más relevante del entorno mecánico para la determinación de la eficiencia direccional del diseño de los huesos que afecta (2,3,34,11-23). La gráfica de la relación hueso/músculo puede estandarizarse para cuantificar el grado relativo de participación de factores mecánicos (tracción/ compresión/torsión/flexión de los huesos por la musculatura)y endocrino-metabólicos en cualquier osteopenia, con proyección terapéutica (111-117). Pueden correlacionarse indicadores de masas ósea y muscular empleando DXA (CMO y masa magra, correlativa de la muscular (118)), o índices de resistencia ósea y fuerza estimada (área de corte) muscular regional empleando QCT o, mejor, pQCT (101105), y también datos directos, dinamométricos, de fuerza muscular. Las relaciones hueso/músculo así determinadas pueden referenciarse estudiando poblaciones numerosas, en forma de cartas de correlación con intervalos de confianza para valores de +/- 1, 2 y 3 DS alrededor de las curvas (Z-scores de la relación hueso/músculo). Nosotros lo hicimos en forma pionera en el País (119) y en Latinoamérica (120-122) empleando DXA (123), por ser la metodología más difundida. Obtuvimos así cartas de referencia antropométricas (no biomecánicas) de las relaciones entre masas óseas y magras 
(no resistencias, ni fuerzas), en niños, niñas, hombres, y mujeres pre y postmenopáusicas (Figura 4-a). Un Z-score de estas relaciones hueso/músculo, calculado para un individuo en estudio, que resulte bajo no sólo en valores absolutos (osteopenia), sino también respecto del estado muscular ('bajo Z-score de la relación hueso/músculo') indicará una interferencia 'sistémica' de un factor endocrino-metabólico en su determinación, y la necesidad de su control farmacológico (124). Una osteopenia con una relación hueso/músculo normal (valores bajos pero proporcionales de indicadores óseos y musculares) indicará su naturaleza 'mecánica' (por desuso), y la necesidad de un tratamiento fisiátrico (125).

A.

\section{CURVAS DE Z-SCORES DE LA RELACIÓN CMO / MM (DEXA)}
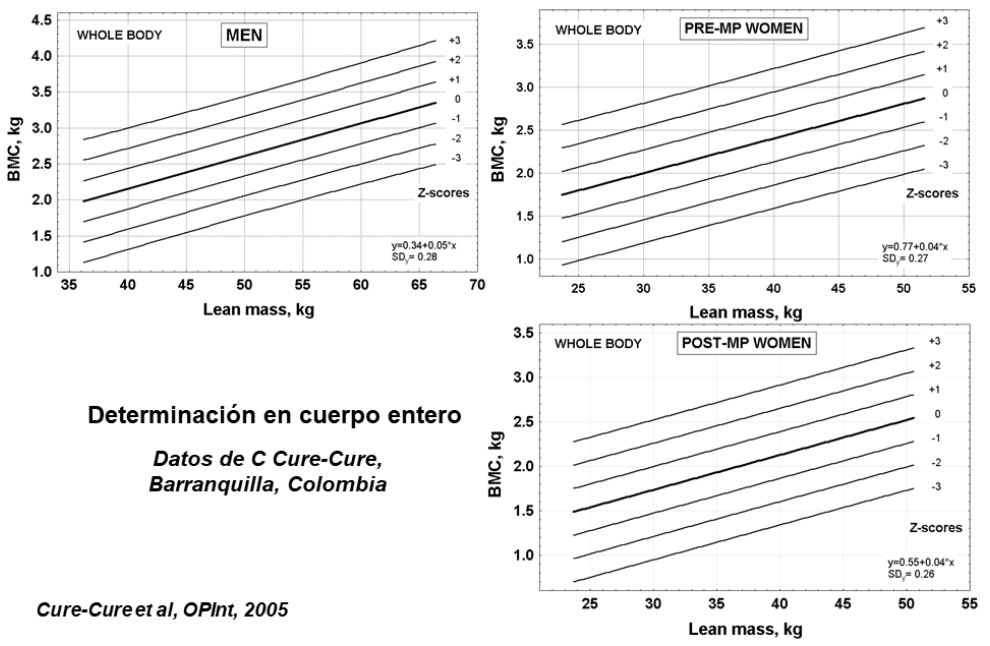

Cure-Cure et al, OPInt, 2005

eterminación en cuerpo entero

Datos de C Cure-Cure, Barranquilla, Colombia

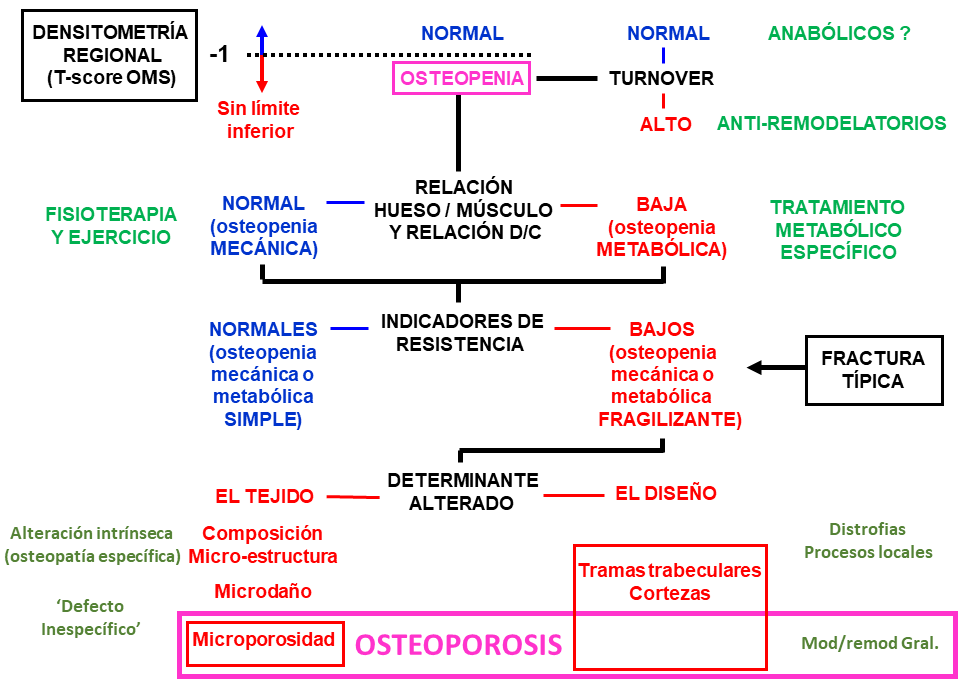

Figura 4. (a) Curvas de referencia Z-scorizadas de relaciones antropométricas hueso/músculo determinadas por DXA en una muestra grande de hombres y de mujeres pre- y post-menopáusicas sanos. Su uso permite determinar, comparativamente, Z-scores individuales de esa relación para diferenciar osteopenias de etiologías 'mecánicas' (por desuso, con déficit de estimulación del mecanostato, en las cuales la relación hueso/músculo tiende a conservarse, para las que cabe indicar tratamientos fisiátricos) y 'sistémicas' (primarias, por alteración original de las células del mecanostato, o secundarias a desplazamientos endocrinometabólicos del punto de referencia del sistema para la detección de 'señales de error' de rigidez ósea, en las cuales la relación hueso/músculo tiende a deteriorarse, para las cuales son necesarios tratamientos farmacológicos). (b) Algoritmo 'ideal' para el diagnóstico de osteopenias y osteoporosis, que describe, en negro, la secuencia de estudios necesaria para identificar y evaluar ambos procesos. Se indican en azul las situaciones normales; en rojo, los resultados anormales; y en verde, los tratamientos que, a grosso modo, estarían indicados en cada caso. En magenta se destacan las posiciones de los diagnósticos de 'osteopenia' y 'osteoporosis', con énfasis en la gran distancia gráfica que los separa, destacándose el carácter eminentemente direccional de los factores interpuestos en el esquema, cuyas implicaciones biomecánicas y clínicas se analizan en el texto. 


\section{Diferencias entre osteopenias y osteoporosis según los nuevos criterios}

La Figura 4-b muestra un esquema operativo tentativo de un diagnóstico 'idealizado' de osteopenias y osteoporosis, que permite, por un lado, apreciar sus inevitables deficiencias actuales; y por otro, comprender en qué consisten las diferencias entre unas y otras:

Una osteopenia puede y debe ser evaluada por DXA, para lo cual pueden aplicarse las escalas de Tscores de la OMS (94), pero sin tener en cuenta límite inferior alguno para distinguir entre osteopenias y osteoporosis (Figura 4-b, arriba). Indicadores bioquímicos del recambio óseo (formación y/o destrucción de hueso) (126-127) pueden distinguir groseramente entre osteopenias con alto o bajo turnover, que requieren inhibidores remodelatorios (mal llamados 'anti-reabsortivos') o agentes pro-modelatorios (mal llamados 'anabólicos'), respectivamente.

El cálculo de los índices de resistencia (107-109) puede calificar la condición de 'fragilidad' propia de la osteopenia estudiada, aunque sin discriminar si la misma se debe a una osteoporosis, a una alteración de la mineralización del tejido óseo (osteomalacia), o a otra patología intrínseca del mismo. Y el análisis de la relación hueso/músculo calificaría la participación relativa de determinantes primarios/ metabólicos y de factores mecánicos en la etiopatogenia de la osteopenia (Figura 4-b, Centro).

De todos modos, aun teniendo en cuenta todos estos criterios de estudio, sólo podríamos diagnosticar una osteoporosis si lográramos, además, descartar una alteración de la calidad del tejido óseo remanente, condición necesaria por definición (Figura 4-b, abajo). Lamentablemente, este diagnóstico se está complicando últimamente, por el descubrimiento de alteraciones cualitativas etarias naturales del tejido mineralizado en mujeres postmenopáusicas, fracturadas y aun sanas $(128,129)$.

En consecuencia, el diagnóstico de osteoporosis requiere, sí o sí, verificar las tres condiciones: 'osteopenia', 'fragilidad' (100) (no importa si es 'mecánica' o 'sistémica'), y 'normalidad del tejido remanente'. Si tenemos en cuenta que la resistencia a la fractura está determinada en forma excluyente por la calidad mecánica del tejido mineralizado y la calidad del diseño del hueso (11-13), es fácil concluir que las osteoporosis serían 'osteopenias de intensidad suficiente como para alterar en forma mecánicamente significativa el diseño óseo'. Un último vistazo a la Figura 4-b (de arriba, izquierda, a abajo, derecha) ayudará a advertir la enorme distancia que separa los diagnósticos de osteopenia y de osteoporosis, y la naturaleza eminentemente direccional de las variables involucradas en las correspondientes propiedades.

En pocas palabras, nuestros trabajos permiten apoyar la proposición original que considera que:

Las osteoporosis son enfermedades del diseño óseo.

En eso consiste su diferencia con las osteopenias, cualquiera sea su magnitud densitométrica.

'Mi arquitectura es como un organismo vivo. Es biológica'.

Le Corbusier

Fuente de financiamiento: Consejo Nacional de Investigaciones Científicas y Técnicas (CONICET).

\section{Referencias bibliográficas}

\footnotetext{
1. Huiskes R. If bone is the answer, then which is the question? J Anat 2000;197(2):145 — 56.

2. Frost HM, Ferretti JL, Jee WSS. Some roles of mechanical usage, muscle strength and the mechanostat in skeletal physiology, disease, and research. Calcif Tissue Int 1997;62(1):1-7.

3. Frost HM (ed). The Utah Paradigm of Skeletal Physiology. ISMNI, Atenas, 2005.

4. Ferretti JL, Frost HM, High W, Jee W, Jerome C, Mosekilde L, Thompson D. Osteoporosis research: its focus and some insights from a new paradigm (editorial). Calcif Tissue Int 1995;57(6):399-404.

5. Ferretti JL, Cointry GR, Capozza RF. De la Osteología a la Osteo-miología. Tres décadas de aportes originales continuos al análisis biomecánico osteomuscular. Actualizaciones en Osteología (BA) 2018(2);14:125-47.

6. Hall BK (ed). Bones and Cartilage. Developmental \& Evolutionary Skeletal Biology, 2nd Ed. Elsevier, Amsterdam, 2015.

7. Wainwright SA, Biggs WD, Currey JD, Gossline JM (eds). Mechanical Design in Organisms. Edward Arnold, Londres, 1976.

8. Frost HM. Bone's mechanostat: a 2003 update. Anat Rec A Discov Mol Cel Evol Biol 2003;275(2):1081-101.

9. Tavassoly I, Goldfarb J, Iyengar R. Systems Biology Primer: basic methods and approaches. Essays Biochem 2018;62(4):487-500.

10. Ferretti JL. Biología General de los esqueletos. En: Osteoporosis. Zanchetta JR )ed), pp 3-6. Panamericana, BsAs, 2001.
} 
11. Martin RB, Burr DB, Sharkey NA (eds). Skeletal Tissue Mechanics. Springer, NY, 1998

12. Ferretti JL. Biomechanical properties of bones. En: Bone Densitometry and Osteoporosis. Genant HK, Guglielmi G, Jergas M (eds), Springer, Berlín, 1998.

13. Ferretti JL, Capozza R, Cointry G. Propiedades biomecánicas óseas. En: Osteoporosis. Zanchetta J (ed), Panamericana, BsAs, pp 39-50,2001.

14. Garnero P. Role of collagen organization on the properties of bone. Calcif Tissue Int 2015;97(3):229—40.

15. Warshaw J, Bromage TG, Terranova CJ, Enlow DH. Collagen fiber orientation in primate long bones. Anat Rec 2017, 300(7):1189-1207.

16. Allison SJ, Poole KES, Treece GM, Gee AH, Tonkin C, Rennie WJ, Folland JP, Summers GD, Brooke-Wavell IG. The influence of high-impact exercise on cortical and trabecular bone mineral content and 3D distribution across the proximal femur in older men. J Bone Miner Res 2015;30(9):1709-16.

17. Recker RR (ed). Bone Histomorphometry: Techniques and Interpretation. CRC Press, Boca Raton (FL), 1983.

18. Frost HM. Structural adaptations to mechanical usage: 1. Redefining Wolff's Law: The bone modeling problem. Anat Rec 1990;226(4):403-13.

19. Frost HM. Structural adaptations to mechanical usage: 1. Redefining Wolff's Law: The bone remodeling problem. Anat Rec 1990;226(4):414-22.

20. Granke M, Grimal Q, Saïed A, Nauleau P, Peyrin F, Laugier P. Change in porosity is the major determinant of the variation of cortical bone elasticity at the millimeter scale in aged women. Bone 2011;49(5):1020—6.

21. Ferretti JL, Cointry G, Capozza R. Osteocitos mirando hacia arriba (o “La estructura ósea vista desde abajo"). Actualizaciones en Osteología (BA) 2014;10(1):45-82.

22. Belaadi N, Aureille J, Guilluy C. Under pressure: Mechanical stress management in the nucleus. Cells 2016;5(1):27-36.

23. Varsa A, Breuls RG, Semeins CM, Salmon PI, Klein—Nulend J. Osteocyte morphology in fibula and calvaria-is there any role for mechanosensing? Bone 2008;43(3):452-58

24. Van Oers RFM, Wang H, Bacabac RG. Osteocyte shape and mechanical loading. Curr Osteoporos Rep 2015;13(2):61-66.

25. Pavalko FM, Norvell SM, Burr DB, Turner CH, Duncan RL, Bidwell JP. A model for mechanotransduction in bone cells: The load-bearing mechanosomes. J Cell Biochem 2003;88(1):104-12.

26. Cho S, Irianto J, Discher DE. Mechanosensing by the nucleus: From pathways to scaling relationships. J Cell Biol 2017, 216(2):305-315

27. Galea GL, Lanyon LE, Price JS. Sclerostin's role in bone's adaptive response to mechanical loading. Bone 2017;96:38-44.

28. Delgado—Calle J, Bellido T. Osteocytes and skeletal pathophysiology. Curr Mol Bio Rep 2015;1(4):157—67.

29. Capozza R, Nocciolino L, Cointry G, Ferretti JL. Cooperación biofísico-bioquímica en el control direcional de la 'calidad estructural' ósea. Actualizaciones en Osteología (BA) 2015,11(2):1136-50.

30. Wolff J (ed). Das Gesetz der Transformation der Knochen. Hirschwald, Berlin, 1892

31. Frost HM. The Utah Paradigm of skeletal physiology: An overview of its insights for bone, cartilage and collagenous tissue organs. J Bone Miner Metab 2000;18:278-82.

32. Ferretti JL, Cointry GR, Capozza RF, Frost HM. Bone mass, bone strength, muscle-bone interactions, osteopenias and osteoporoses. Mech Ageing Dev 2003(3);124:269-79.

33. Ferretti JL, Frost HM. Osteopenias and osteoporoses - Muscle—bone interactions, absorptiometry, safety factors, and fracture risk. En: Orthopaedic Issues in Osteoporosis. An YH (ed), CRC Press, Boca Raton (FL) 2003.

34. Ferretti JL, Cointry G, Capozza R. Regulación biomecánica y modulación endocrino-metabólica de la eficiencia estructural ósea. En: Osteoporosis. Zanchetta JR (ed), pp 73—98. Panamericana, BsAs, 2001.

35. Capozza R, Feldman S, Mortarino P, Reina P, Schiessl H, Rittweger J, Ferretti JL, Cointry G. Structural analysis of the human tibia by tomographic (pQCT) serial scans. J Anat 2010;216(4):470-81.

36. Cointry G, Nocciolino L, Ireland A, Hall N, Kriechbaumer A, Ferretti JL, Rittweger J, Capozza R. Structural differences in cortical properties between upper and lower human fibula as described by pQCT serial scans. A biomechanical interpretation. Bone 2016;90:185—94

37. Rittweger J, Felsenberg D, Maganaris C, Ferretti JL. Vertical jumping performance after 90 days bed rest with and without flywheel resistive exercise, including a 180 days follow—up. Eur J Appl Physiol 2007;100(4):427-36.

38. Wilks D, Winwood K, Gilliver S, Michaelis I, Kwiet A, Sun L, Ferretti JL, Sargeant A, Felsenberg D, Rittweger J. Bone mass and geometry of the tibia and the radius of Master sprinters, middle and long—distance runners, race—walkers, and sedentary control participants. Bone 2009;45(1):91—97.

39. Feldman S, Capozza RF, Mortarino PA, Reina PS, Ferretti JL, Rittweger J, Cointry GR. Site and sex effects on tibia structure in distance runners and untrained people. Med Sci Sports Exerc 2012;44(8):1580-8.

40. Lüscher SH, Pilot N, Pisani L, Nocciolino L, Ireland A, Rittweger J, Ferretti JL, Cointry GR, Capozza RF. Differences in the cortical structure of the whole fibula and tibia between long-distance runners and untrained controls. Toward a wider conception of the biomechanical regulation of cortical bone structure. Front Endocrinol 2019, 10:833; doi:10.3389/fendo.2019.00833.

41. Ferretti JL, Spiaggi E, Capozza R, Cointry G, Zanchetta J. Interrelationships between geometric and mechanical properties of long bones from three rodent species with very different biomass. Phylogenetic implications. J Bone Miner Res 1992; 7 Suppl 2: S423—5.

42. Ferretti JL, Capozza R, Mondelo N, Montuori E, Zanchetta J. Determination of femur structural properties by geometric and material variables as a function of body weight in rats. Evidence of a sexual dimorphism. Bone 1993;14(3):265-70.

43. Ferretti JL, Capozza R, Mondelo N, Zanchetta J. Interrelationships between densitometrical, geometric and mechanical properties of rat femurs. Inferences concerning mechanical regulation of bone modeling. J Bone Miner Res 1993;8(11):1389—96.

44. Capozza R, Rittweger J, Reina P, Mortarino P, Nocciolino L, Feldman S, Ferretti JL, Cointry G. pQCT—assessed relationships between diaphyseal design and cortical bone mass density in the tibiae of healthy sedentary and trained men and women. J Musculoskel Neuron Interact 2013;13(2):195-205. 
45. Currey JD. Incompatible mechanical properties in compact bone. J Theor Biol 2004;231(4):569—80.

46. Di Masso R, Font MT, Capozza R, Detarsio G, Sosa F, Ferretti JL. Long-bone biomechanics in mice selected for body conformation. Bone 1997(6);20:539-45.

47. Vera MC, Ferretti JL, Abdala V, Cointry G. Biomechanical properties of anuran long bones: correlations with locomotor modes and habitat use. J Anat 2020, 236(6):1112-1125.

48. Ferretti JL, Cointry G, Capozza R, Montuori E, Roldán E, Pérez Lloret A. Biomechanical effects of the full range of useful doses of (3-amino-1— hydroxypropylidene)-1,1-bisphosphonate (APD) on femur diaphysis and cortical bone tissue in rats. Bone Miner 1990;11(1):111.22.

49. Ferretti JL, Delgado C, Capozza R, Cointry G, Montuori E, Roldán E, Pérez Lloret A, Zanchetta J. Protective effects of disodium etidronate and pamidronate against the biomechanical repercussion of betamethasone-induced osteopenia in growing rat femurs. Bone Miner 1993;20(3):265-76.

50. Ferretti JL, Mondelo N, Capozza R, Cointry G, Zanchetta J. Effects of large doses of olpadronate (dimethyl—pamidronate) on mineral density, cross—sectional architecture, and mechanical properties of rat femurs. Bone 1995;16(4S):285S—93S.

51. Ma Y, Ferretti JL, Capozza R, Cointry G, Alippi R, Zanchetta J, Jee WSS. Tomographical (pQCT) description and correlation with histomorphometric changes in tibial cancellous bone. Bone 1995;17(4S):321S-27S.

52. Cointry G, Mondelo N, Zanchetta J, Montuori E. Ferretti JL. Intravenous olpadronate restores ovariectomy-affected bone strength. A mechanical, densitometric and tomographic (pQCT) study. Bone 1995;17(4S):373S-78S

53. Cointry G, Capozza R, Chiappe M, Feldman S, Meta M, Daniele S, Fracalossi N, Reina P, Ferretti JL. Novel experimental effects on bone material's properties and the pre — and post—yield behavior of bones may be independent of bone mineralization. J Bone Miner Metab 2005;23(S):30—5.

54. Capozza R, Mondelo N, Reina P, Nocciolino L, Meta M, Ferretti JL. Mineralization - and remodeling - unrelated effects of high doses of olpadronate (dimethyl-pamidronate) on the pre - and post-yield properties of rat cortical bone. J Musculoskel Neuron Interact 2103;13(2):185-94.

55. Roldán E, Pérez Lloret A, Ferretti JL. Olpadronate: a new amino-bisphosphonate for the treatment of medical osteopathies. Expert Opin Invest Drugs 1998;7(9):1521-28.

56. Ferretti JL. Effects of bisphosphonates on bone biomechanics. En: Bisphosphonate on Bones. Bijvoet O et al (eds), pp 211-29. Elsevier, Amsterdam, 1995

57. Papapoulos S, Ferretti JL, Labriola R, Mondelo N, Roldán EJ. Patent Family: Bone Mass Anabolic Composition ([3—(N,N—dimethylamine)—1— Hydroxypropylidene]—bisphosphonate, or Olpadronate). European Application 94120799.5, 1995. Extensions to USA, Sudáfrica, Australia, Corea, Brasil, 1997-99.

58. Ferretti JL, Delgado C, Ghersevich S, Augsburger S. Biomechanical description of corticoid osteoporosis in rat long bones. En: Calcium Regulation \& Bone Metabolism: Basic \& Clinical Aspects, Vol 9. Cohn D, Martin T, Meunier P (eds), p 668. Elsevier, Amsterdam, 1987.

59. Ferretti JL, Vázquez SL, Delgado C, Capozza R, Cointry G. Biphasic dose-response curves of cortisol effects on rat diaphyseal bone biomechanics. Calcif Tissue Int 1992;50(1):49-54.

60. Ferretti JL, Capozza R, Cointry G, Delgado C, Zanchetta J. Monophasic dose-response curves of betamethasone on geometric and mechanical properties of femur diaphysis in growing rats. Bone 1995;16(1):103-8.

61. Ferretti JL, Olivera M, Zanchetta J, Bozzini CE. Dexamethasone effects on structural, geometric and material properties of rat femur diaphyses as described by peripheral quantitative computed tomography (pQCT) and bending tests. Bone 1995;16(1):119—24.

62. Ferretti JL, Tessaro RD, Audisio EO, Galassi CD. Long-term effects of high or low Ca intakes and of lack of parathyroid function on rat femur biomechanics. Calcif Tiss Int 1985;37(6):608-12.

63. Capozza R, Ferretti JL, Ma Y, Meta M, Alippi R, Zanchetta J, Jee WSS. Tomographic (pQCT) and biomechanical effects of PTH(1-38) on chronically immobilized or overload rat femurs. Bone 1995;17(4S):233S-39S.

64. Ferretti JL, Audisio E, Tessaro R, Galassi C, Masoni A, Puche RC. Effect of cholecalciferol, 25(OH)cholecalciferol and 1,25-(HO)2-cholecalciferol on the mechanical properties of femurs of rachitic chicks fed a P—deficient diet. Nutr Rep Int 1984;29:213—6.

65. Audisio E, Ostera D, García Véscovi E, Ferretti JL. Dose-response curves of cholecalciferol effects on biomechanical properties of rachitic chick femurs. Nutr Rep Int 1985;32:1139—44.

66. Feldman S, Cointry G, Sarrió L, Ferretti JL, Capozza R. Effects of hypophysectomy and growth hormone replacement on cortical bone structure and biomechanics in rats. Bone 2004;34(1):203-15.

67. Álvarez-Lloret P, Fernández J, Molinuevo M, Lino A, Ferretti JL, Capozza R, Cortizo A, McCarthy A. Multiscale approach for the evaluation of bone mineralization in strontium ranelate—-treated diabetic rats. Biol Trace Elem Res 2018, 186(2):457—466.

68. Cointry G, Negri AL, Ferretti JL. Biomechanical impact of aluminum accumulation in rat cortical bone. J Bone Miner Metab 2005;23(1):15-23.

69. Ferretti JL Tessaro R, Delgado C, Bozzini C, Alippi R, Barceló AC. Biomechanical performance of diaphyseal shafts and bone tissue of femurs from protein—restricted rats. Bone Miner 1988;4(4):329—41.

70. Alippi R, Meta M, Bozzini C, Olivera M, Ferretti JL, Bozzini CE. Dynamics and recovery of morphometrical variables and pQCT—derived cortical bone properties after a short—-term protein restriction in maturing rats. Growth Devel Aging 2001;65(2):67-72.

71. Schneider P, Reiners C, Cointry G, Capozza R, Ferretti JL. Bone quality parameters of the distal radius as assessed by pQCT in normal and fractured women. Osteoporos Int 2001;12(8):639-46.

72. Roldán E, Capiglioni R, Cointry G, Capozza R, Ferretti JL. Postmenopausal changes in the distribution of the volumetric BMD of cortical bone. J Musculoskel Neuron Interact 2001;2(2):157—62. 
73. Zanchetta J, Bogado C, Ferretti JL, Wang O, Wilson M, Sato M, Gaich G, Dalsky G, Myers S. Effects of teriparatide [recombinant human parathyroid hormone (1-34)] on cortical bone in postmenopausal women with osteoporosis. J Bone Miner Res 2003;18(3):539—43.

74. Ferretti JL, Mazure R, Tanoue P, Marino A, Cointry G, Vázquez H, Niveloni S, Pedreira S, Mauriño E, Zanchetta J, Bai JC. Analysis of the structure and strength of bones in celiac disease patients. Amer J Gastroenterol 2003;98(2):382—90.

75. Schneider P. Biko J, Reiners C, Demidchik Y, Drozd V, Capozza R, Cointry G, Ferretti JL. Impact of parathyroid status and vitamin-D supplementation on bone mass and muscle-bone relationships in 208 Belarussian children after thyroidectomy because of thyroid carcinoma. Exp Clin Endocrinol Metab 2004;112(8):444-50.

76. Cummings SR, Ferrari S, Eastell R, Gilchrist N, Back Jemsen JE, McClung M, Roux C, Törring O, Valter I, Wang AT, Brown JP. Vertebral fractures after discontinuation of denosumab: a post-hoc analysis of the randomized placebo—controlled FREEDOM Trial and its extension. J Bone Miner Res 2018;33(2):190-8.

77. Tripto-Shkolnik L, Fund N, Rouach V, Chodick G, Shalev V, Goldshtein I. Fracture incidence after denosumab discontinuation: real-world data from a large healthcare provider. Bone 2020, doi.org/10.1016/j.bone-2019.115150.

78. Lamy O, Fernández-Fernández E, Monjo-Henry I, Stoll D, Aubry-Rozier B, Benavent-Núñez D, Aguado P. González—Rodríguez E. Alendronate after denosumab discontinuation in women previously exposed to bisphosphonates was not effective in preventing the risk of spontaneous multiple vertebral fractures: two case reports. Osteoporos Int 2019, 30(5):1111-1115.

79. Roldán E, Ferretti JL. How do anti—osteoporotic agents prevent fractures? Bone 2000;26(4):393—6.

80. Ferretti JL, Capozza R, Cointry G. Why does a bone break. Arch Osteoporos 2012;7(S1):S128—29.

81. Ireland A, Capozza R, Cointry G, Nocciolino L, Ferretti JL, Rittweger J. Meagre effects of disuse on the human fibula are not explained by bone size or geometry. Osteopor Int 2017;28(2):633-41.

82. Nocciolino L, Lüscher S, Pilot N, Pisani L, Mackler L, Cointry G, Ireland A, Rittweger J, Ferretti JL, Capozza R. Evidencia original directa (dinamométrico-tomográfica) de la influencia sitio—específica de la musculatura sobre la estructura ósea. Hacia una concepción más amplia del mecanostato. Actualizaciones en Osteología (BA) 2018;14(2):178-83.

83. Cristofolini L, Conti G, Juszczyk M, Cremonini S, Van Sin Jan S, Viceconti M. Structural behavior and strain distribution of the long bones of the human lower limbs. J Biomech 2010;43(5):826-35.

84. Marchi D, Shaw CN. Variation of fibular robusticity reflects variation in mobility patterns. J Hum Evol 2011;61(5):609-16

85. Barnett CH, Napier JR. The rotatory motility of the fibula in eutherian mammals. J Anat 1953;87(1):11-21.

86. Bramble DM, Lieberman DE. Endurance running and the evolution of Homo. Nature 2004;432(7015):345-52.

87. Rittweger J, Ireland A, Lüscher S, Nocciolino LM, Pilot N, Pisani L, Cointry GR, Ferretti JL, Capozza RF. Fibula: The forgotten bone - May it provide some insight on a wider scope of bone mechanostat control? Curr Osteopor Rep 2018. 16(6):775-778

88. Bertram JE, Biewener AA. Bone curvature sacrificing strength for load predictability? J Theor Biol 1988;131(1):75—92.

89. Pearson OM, Lieberman DE. The aging of Wolff's "Law": ontogeny and responses to mechanical loading in cortical bone. Am J Phys Anthropol.2004; Suppl 39:63-99.

90. Frost HM. On the estrogen—bone relationship and postmenopausal bone loss: A new model. J Bone Miner Res 1999;14(9):1473—7.

91. Cointry G, Capozza R, Feldman S, Reina P, Grappiolo I, Ferretti SE, Mortarino P, Chiappe M, Ferretti JL. ¿Los huesos son estructuras genéticas, metabólicas, biomecánicas, o todo a la vez? Actualizaciones en Osteología (BA) 2009;5(3):185-95.

92. Kanis JA, Melton J, Christiansen C. The diagnosis of osteoporosis. J Bone Miner Res 1994;9(8):1137—42.

93. Albright F, Burnett C, Cope O. Acute atrophy of bone (osteoporosis) simulating hyperparathyroidism. J Clin Endocrinol Metab 1941; 1(9): 711—6.

94. Consensus Development Conference: Diagnosis, Prophylaxis and Treatment of Osteoporosis. Am J Med 1993;94(6):646—50.

95. Frost HM, Schönau E. The 'muscle—bone unit' in children and adolescents: a 2000 overview. J Pediatr Endocrinol Metab 2000;13(6):571—90.

96. NIH Consensus Development Panel on Osteoporosis Prevention, Diagnosis, and Therapy. JAMA 2001;285(6):785-91.

97. Järvinen T, Michaëlsson K, Jokihaara J, Collins GS, Perry TL, Mintzes B, Musini V, Erviti J, Gorricho J, Wright JM, Sievänen H. Overdiagnosis of bone fragility in the quest to prevent hip fracture. Br Med J 2015, 350:h2088.

98. Leslie WD, Majumdar SR, Morin SN, Lix LM. Why does rate of bone density loss not predict fracture risk? J Clin Endocrinol Metab 2015;100(2):679-83.

99. Wilkin T. Changing perceptions in osteoporosis. Brit Med J 1999;318(7187):862-5.

100. Choski P, Jepsen KJ, Clines GA. The challenges of diagnosing osteoporosis and the limitations of currently available tools. Clin Diab Endocrinol 2018;4:12-17.

101. Ferretti JL. Perspectives of pQCT technology associated to biomechanical studies in skeletal research employing animal models. Bone 1995; 17(4 Suppl):353S-64S.

102. Ferretti JL. Peripheral quantitative computed tomography for evaluating structural and mechanical properties of small bone. En: Mechanical Testing of Bone and the Bone-Implant Interface. An YH, Draughn RA (eds), CRC Press, Boca Raton (FL), 2000.

103. Ferretti JL, Cointry GR, Capozza RF. Noninvasive analysis of bone mass, structure, and strength. En: Orthopaedic Issues in Osteoporosis. An YH (ed), pp 145-67. CRC Press, Boca Raton (FL). 2002.

104. Ferretti JL. Determinación no—invasiva de las propiedades biomecánicas óseas. En: Osteoporosis. Zanchetta J (ed), pp 39—50. Panamericana, BsAs, 2001.

105. Ohlsson C, Snud D, Wallerck A, Nilsson M, Karlsson M, Johansson H, Melleström D, Lorentzon M. Cortical bone area predicts incident fractures independently of areal bone mineral density in older men. J Clin Endocrinol Metab 2017(2);102:516-24. 
106. Mikolajewicz N, Bishop N, Burghardt A, Folkestad L, Hall A, Glorieux FH. HR—pQCT measures of bone microarchitecture predict fracture: systematic review and meta—analysis. J Bone Miner Res 2019, 35(3):446—459.

107. Ferretti JL, Capozza R, Zanchetta JR. Mechanical validation of a tomographic (pQCT) index for noninvasive assessment of rat femur bending strength. Bone 1996;18(2):97-102.

108. Cointry G, Ferretti JL, Reina P, Nocciolino L, Rittweger J, Capozza R. The pQCT ‘Bone Strength Indices'. Relative mechanical impact and diagnostic value of the indicators of bone tissue design and quality employed in their calculation in healthy men and pre — and post—menopausal women. J Musculoskel Neuron Interact 2014;14(1):29—40.

109. Schiessl H, Ferretti JL, Niemeyer G, Willnecker J. Noninvasive bone strength index as analyzed by peripheral quantitative computed tomography (pQCT). En: Paediatric Osteology. Schönau E (ed). Elsevier, Amsterdam, 1996; pp 141—5.

110. Schiessl H, Ferretti JL, Tysarczyk - Niemeyer G, Willnecker J, Wilhelm G. The role of muscles in the mechanical adaptation of bone. En: Advances in Osteoporosis, Vol 1. Lyritis GP (ed), pp 53-62. Hylonome, Atenas, 1998.

111. Ireland A, Ferretti JL, Rittweger J. Imaging the muscle—bone relationship. Curr osteoporos Rep 2014;12(4):486—95.

112. Reina P, Cointry G, Nocciolino L, Feldman S, Ferretti JL, Rittweger J, Capozza R. Analysis of the independent power of age-related, anthropometric and mechanical factors as determinants of the structure of radius and tibia in normal adults. J Musculoskel Neuron Interact 2015;15(1):10-22.

113. Ferretti JL, Capozza R,, Cointry G, Capiglioni R, Roldán E, Zanchetta J. Densitometric and tomographic analysis of musculoskeletal interactions in humans. J Musculoskel Neuron Interact 2000;1(1):18-21.

114. Ferretti JL, Cointry G, Capozza R, Capiglioni R, Chiappe M. Analysis of biomechanical effects on bone and on the muscle-bone interactions in small animal models. J Musculoskel Neuron Interact 2001;1(3):263-74.

115. Cointry G, Capozza RF, Negri AL, Roldán EJ, Ferretti JL. Biomechanical background for a noninvasive assessment of bone strength and musclebone interactions. J Musculoskel Neuron Interact 2004;4(1):1-11.

116. Capozza R, Cointry G, Ferretti SE, Feldman S, Reina P, Fracalossi M, Ulla M, Cure —Cure C, Ferretti JL. Absorptiometric assessment of musclebon relationships in humans. Reference, validation, and application studies. J Bone Miner Metab 2005;23(S):109—14.

117. Rittweger J, Ferretti JL. Imaging mechanical muscle—bone relationships: How to see the invisible. Clin Rev Bone Miner Metab 2014(4);12:66-76.

118. Ferretti JL, Schiessl H, Frost HM. On new opportunities for absorptiometry. J Clin Densitom 1998;1(1):41—53.

119. Ferretti JL, Capozza RF, Cointry GR, García S, Plotkin H, Álvarez Filgueira M, Zanchetta J. Gender—related differences in the relationships between densitometric values of whole-body bone mineral content and lean mass in humans between 2 and 87 years of age. Bone 1998;22(6):683-90.

120. Capozza R, Cointry G, Cure-Ramírez R, Ferretti JL, Cure-Cure C. A DXA study of muscle—bone relationships in the whole body and limbs of 2,512 normal men and pre— and post—-menopausal women. Bone 2004;35(1):283—95.

121. Cure-Cure C, Capozza R, Cointry G, Meta M, Ulla M, Cure-Ramírez P, Ferretti JL. Reference charts for the relationships between DXAassessed bone mineral content and lean mass in 3,063 normal men and pre — and post — menopausal women. Ostoporos Int 2005;16(12):2095— 2106 .

122. Denova-Gutiérrez E, Clark P, Capozza R, Nocciolino L, Ferretti JL, Velázquez-Cruz R, Rivera B, Cointry G, Salmerón J. Differences in the relation between bone mineral content and lean mass according to gender and reproductive status by age ranges. J Bone Miner Metab 2019;37(4):749-58.

123. Ferretti JL, Cointry GR, Capozza RF, Zanchetta JR. Dual energy X-ray absorptiometry. En: Skeletal Muscle: Pathology, Diagnosis, and Management of Disease. Preedy VR, Peters TJ (eds), pp 451-8. Greenwich Medical Media, Londres, 2001.

124. Capozza R, Cure-Cure C, Cointry G, Meta M;, Cure P, Rittweger J, Ferretti JL. Association between low lean body mass and osteoporotic fractures after menopause. Menopause 2008;15(5):1-9.

125. Ferretti JL, Frost HM. Hacia un diagnóstico antropométrico de las osteopenias y un diagnóstico biomecánico de las osteoporosis. Medicina (BA) 2003;63(6):737-47.

126. Szulc P. Bone turnover: Biology and assessment tools. Best Pract Res Clin Endocrinol Metab 2018;32(5):725-38.

127. Buehlmeier J, Frings-Meuthen P, Mohorko N, Lau P, Mazzucco S, Ferretti JL, Biolo G, Pisot R, Simunic B, Rittweger J. Markers of bone metabolism during 14 days of bed rest in young and older men. J Musculoskel Neuron Interact 2017;17(1):399—408.

128. Burr DB. Changes in bone matrix with aging. Bone 2019;120:85-93.

129. Rokidi S, Paschalis EP, Klaushofer K, Vennin S, Desyatova A, Turner JA, Watson P, Lappe J, Akhter MP, Recker RR. Organic matrix quality discriminates between age - and BMD - matched fracturing versus non-fracturing post-menopausal women: A pilot study. Bone 2019;127:207-14. 